\title{
РЕВОЛЮЦИЯ 1905-1907 Г.Г. И АРМИЯ (ПО ВОСПОМИНАНИЯМ ВОЕННОГО МИНИСТРА А.Ф. РЕДИГЕРА)
}

\section{THE REVOLUTION OF 1905-1907 AND THE ARMY (ACCORDING TO THE MEMOIRS OF THE MINISTER OF WAR A.F. REDIGER) \\ A. Kuksin \\ A. Barybin \\ A. Vasilyev}

Summary: Russian-Japanese war of 1904-1905 and the revolution of 1905 -1907 on the state of the Russian armed forces are considered in the article, based on the research of the memoirs of the Minister of war A.F. Rediger. The main causes of the «revolutionary ferment» in the Russian army are analyzed.

Keywords: Russian-Japanese war of 1904-1905, revolution of 1905-1907, army, sailors, soldiers, officers.
Куксин Алексей Игоревич

К.и.н., доцент, Егорьевский технологический институт (филиал) ФГБОУ ВО МГТУ «СТАНКИН»

aik71@bk.ru

Барыбин Алексей Валентинович

К.n.н., доцент, Егорьевский технологический институт (филиал) ФГБОУ ВО МГТУ «СТАНКИН» barybinav60@gmail.com

Васильев Алексей Георгиевич

Старший преподаватель, Егорьевский технологический институm (филиал) ФГБОУ ВО МГТУ «СТАНКИН»

alex_vas@ro.ru

Аннотация: В статье, на основе исследования воспоминаний военного министра А.Ф. Редигера, рассматривается влияние русско-японской войны 1904 -1905 гг. и революции 1905 -1907 гг. на состояние вооруженных сил России, анализируются основные причинные «революционного брожения» в русской армии.

Ключевые слова: русско-японская войны 1904 -1905 гг., революция 1905-1907 гг., армия, матросы, солдаты, офицерский состав.

партии социалистов революционеров, а не агитацией большевиков.

Сами выступления в армии и на флоте, в советской исторической литературе оценивались как «массовые», а для подтверждения подобной оценки, приводились следующие данные: в течение 1905 г. - в вооруженных силах произошло не менее 270 открытых выступлений [3, с. 91]. В следующем же году - 21 восстание и 230 невооруженных выступлений [3, с. 147].

Но корректно ли механически суммировать показатели по армии и флоту, и возможно ли все выступления оценивать как «революционные»?

Обратимся к воспоминаниям А.Ф. Редигера. Можно сразу отметить - у военного министра к флоту было особое отношение, а оценивал он его, из-за продолжавшихся в военно-морских силах беспорядков, как элемент опасный не только для государства... [1, т.1, с. 449], но, даже и для страны в целом [1, т.1, с. 502].

Действительно, именно в военно-морских силах произошли самые серьезные восстания. В 1905 году, 14-25 июня случился бунт на броненосце «Потемкин», восстания имели место 15-18 июля в Либаве, 26-27 сентября - в Кронштадте и 11-16 ноября в Севастополе.

В 1906 г. 17-20 июля произошло серьезное выступле- 
ние - в Свеаборге, охватившее и Кронштадт.

Но если солдаты и принимали в этих восстаниях некоторое участие, то, по мнению военного министра, прежде всего, под влиянием матросов. В подтверждение своей точки зрения, он приводит различия в условиях несения службы нижними чинами армии и флота. Арестованные матросы, имели полную возможность «издеваться» над солдатами, которые несли караульную службу в приморских крепостях, получая пищу и одежду худшего качества, чем сами «бунтовщики» [1, т.1, с. 477].

Но именно на армию была возложена главная задача усмирения, причем, по мнению А.Ф. Редигера, «курьезность положения», заключалось в том, гарнизон крепости, в задачу которого входила охрана крепости от флотских бунтовщиков, через коменданта подчинялся именно флотскому начальству [1, т.1, с. 502].

«Перевоспитывать» матросов предполагалось так же, в армейских частях. Военный министр сообщает, что армии пришлось принять в августе 1905 г. 3 тысячи «отбросов» флота и пополнить ими два резервных батальона на Кавказе, чтобы сократить состав флотских экипажей, превратившихся в настоящие «вооруженные банды» [1, т.1, с. 449]. Результат данных действий достаточно успешен, батальоны служили вполне удовлетворительно.

Причины же создавшегося на флоте положения заключались в следующем: особое значение имел такой фактор как «социальное происхождение» - среди матросов было много бывших представителей пролетариата. Кроме того, часть нижних чинов флота, зимой работала на заводах вместе с вольнонаемными рабочими, да и вести революционную агитацию представителям радикальных партий в портовых городах было менее затруднительно.

Но главное, по мнению военного министра, заключалось в следующем: во-первых, лучшие офицеры были отправлены на Восток с эскадрами 3.П. Рожественского и Н.И. Небогатова, а в оставшихся в европейской части России экипажах несколькими ротами командовал всего лишь один офицер, причем, переведенный из армейских частей или механик. Во-вторых, сама система комплектования экипажей флота серьезно отличалась от армейской: матросы изучали свои специальности в разных школах, весной для похода собиралась команда, которая осенью вновь распускалась. Даже боцманы не могли отобрать надежных (в политическом отношении) нижних чинов, поскольку личный состав флота был неудовлетворительно [1, т.1, с. 503].

Таким образом, даже сокращение флота являлось большой проблемой, а вывод А.Ф. Редигера получался крайне пессимистичным: что мы «сухопутные», морской службы не знали, поэтому оспаривать вывод о необходимости сокращении флота не могли. Однако, здравый смысл все же подсказывал что если в военно-морских силах не произойдут серьезные перемены, флот останется ненадежным, и, фактически, даже опасным для государства [1, т.1, с. 504].

Несколько иным было положение в сухопутных войсках. Хотя здесь встречались и сходные проблемы, касавшиеся офицерского состава. По словам А.Ф. Редигер, воинские части, остававшиеся в европейской части России были полностью дезорганизованы. Причиной же послужило откомандирование лучших офицеров и солдат в действующую армию, где в то время происходило формирование огромных по численности военных учреждений, затеянное «по безумной фантазии» командующего действующей армией Куропаткина [1, т.1, с. 477].

В воинских частях постоянно наблюдался некомплект офицеров, да и их качества не всегда соответствовали сложной обстановке 1905-1907 гг. Как сообщал в своем отчете военному министру за 1905 г. командующий войсками Московского военного округа (далее МВО - А.К.) Ф.К. Гершельман: «Наиболее неблагонадежным элементом являлись присланные из запаса прапорщики». Офицерский состав пополнялся за счет военнослужащих, переведенных из других частей, призванных из запаса и зауряд-прапорщиками, что не могло не сказаться на ухудшении качества всех частей корпуса. Поэтому, командующий $\mathrm{MBO}$, просил по возможности, при следующих мобилизациях, оставлять в воинских частях весь «коренной» офицерский состав [4, с. 61].

Вторая важная причина дезорганизации вооруженных сил (поскольку, общая революционная ситуация в стране, конечно, не могла не отражаться и на армии), указанная А.Ф. Редигером - «феномен запасных». Военный министр отмечает плохую дисциплину вызванных из запаса нижних чинов, недовольных тем, что их задерживают на службе даже после заключения мира. К тому же, в сложной внутриполитической обстановке в стране, связанной с массовыми беспорядками и забастовками, они не имели представления, о том, что происходит у них дома, как живет в это бурное время семья [1, т.1, с. 476].

Мнение А.Ф. Редигера подтверждают и иные источники. Как отмечал в своих мемуарах генерал А.И. Деникин, «запасные» мало интересовались политическими социальными вопросами. Весьма скептически они относились революционным листовкам и мало прислушивались к речам делегатов, которых отправляли к ним на вокзалах разного рода «народные правительства», созданные революционными деятелями. Главный их лозунг был весьма прост: «Домой!». Именно поэтому, призванные из запаса солдаты, воспринимая свободу как без- 
началие и беззаконие, а значит «буйствовали и бесчинствовали» по всем армейским тылам. Эта «опьяненная воздухом свободы» масса нижних чинов не подчинялась ни приказам армейского начальства, ни увещеваниям «революционных комитетов». Запасные требовали немедленного возвращения домой, совершенно не обращая внимания на возможности подвижного состава сибирских железных дорог, которые растянулись на огромное расстояние в десять тысяч километров $[5$, с. 172].

Итак, если учесть, что в армию было призвано более 1 миллиона запасных, следует считать их роль в общем брожении армии очень значительной, если не преобладающей. Так в восьмидесяти четырех списках требований, предъявленных нижними чинами своим командирам в 1905 г., увольнение в запас фигурирует в сорока шести. [6, с. 250 - 251]. Как сообщал командующий войсками $\mathrm{MBO}$, худшими «нравственными» качествами, отличались именно нижние чины, призванные из запаса, для которых характерными явлениями были буйство, пьянство полное отсутствие дисциплины. Причем некоторые солдаты поддались революционной агитации. В тоже время, командующий делает вполне оптимистичный вывод о том, что после увольнения запасных, нравственное состояние войск стало вполне благонадежным и хорошим [7, с. 59].

Но можно ли считать все это «проблеском» революционного сознания у солдат? Характерный случай произошел во время Красноярского восстания 1905 г., когда 23 декабря несколько эшелонов 7-го Красноярского пехотного полка застряли на станции Злобино проходившей там забастовки железнодорожников «Красноярской республики», созданной Советом красноярских рабочих и солдат. Офицеры просто объяснили солдатам, почему их эшелоны стоят и разъяренные нижние чины буквально за несколько дней, применив оружие, подавили это восстание [8, с. 6 - 9].

Брожение проявлялось в разных формах, поэтому следует внимательно рассматривать каждый отдельный случай, связанный с нарушением воинской дисциплины. Рассматривая «Приказы по войскам МВО» (за 1905-1907 гг.) можно установить, что в большинстве случаев по политическим мотивам нижних чинов привлекали к суду за хранение, но далеко не всегда за распространение нелегальной литературы, за брань, часто в нетрезвом виде, в адрес царствующих особ. Так, самовольно отлучившийся рядовой 20-го гренадерского полка Иван Ковалев пел песни под аккордеон, всячески ругался, оскорбляя Государыню Императрицу [9, № 319 ]. Рядовой 218-го пехотного Борисоглебского полка Евдоким Суслов, пребывая в самовольной отлучке, заочно ругал командира роты, бегал с ружьем и в нетрезвом виде бранил Государя Императора [9, № 74$]$.
Встречались, безусловно, и иные случаи - распространение агитации, членство в революционных партиях, применение оружия против начальства. Однако, для большинства выступлений нижних чинов, характерными чертами являлись стихийность, скоротечность. Как отмечал военный министр, очень часто встречалось крайнее разнообразие требований, когда условие отмены смертной казни и введение всеобщих, равных и тайных выборов, вполне мирно соседствовало с требованиями увольнения запасных и улучшения качества продовольствия и сапог [1, т.1, с. 477].

Осознавая себя особой социальной группой, солдаты часто стремились дистанцироваться от выступлений рабочих и крестьян и даже во время собственных беспорядков в воинских частях, не пускали в казармы штатских агитаторов.

Повод для недовольства у нижних чинов, безусловно, был. По мнению А.Ф. Редигера, солдат действительно жил «в нищенской обстановке», а бывал сытым лишь при особой распорядительности и честности командиров. Жалованье было ничтожным - 2 рубля и 10 копеек в год, а белье же и «сапожный товар», были столь такого неудовлетворительного качества, что, солдатам приходилось продавать их по низкой цене и приобретать вещи за собственный счет. За шитье сапог нижним чинам приходилось доплачивать два рубля из собственного кармана, поэтому, делает вывод военный министр: без помощи «из дому» солдат не просто находился в бедственном положении, но «почти не мог существовать!» [1, т.1, с. 476].

Одеяла и постельное белье было заведено лишь в некоторых частях. Требования, связанные с улучшением быта, прочно занимали в списках бунтующих солдат первое место. Но не менее важно и другое: произведенные в армии улучшения были не столь уж велики - увеличение продуктового довольствия, отпуск постельного белья и одеял, гимнастической рубахи и т.д. Как саркастически сообщает военный министр, военные чиновники собирались исключить из списка улучшений носовые платки, но А.Ф. Редигеру удалось их отстоять [1, т.1, с. 478]. Солдаты были этими нововведениями вполне удовлетворены, и, по словам А.Ф. Редигера: после увольнения призванных из запаса нижних чинов и сравнительно небольшого улучшения солдатского быта, дисциплина в армии была восстановлена, а беспорядки превратились в единичное явление [1, т.1, с. 479].

Наконец, не стоит упускать из виду еще одно важное требование солдат: о прекращении «полицейской службы». Фраза А.Ф. Редигера, обращенная в адрес председателя Совета министров П.А. Столыпина: «Армия не учится, а служит Вам», действительно стала исторической. Именно на вооруженные силы, а не на полицию, верховная власть возложила ответственность за подавление 
революции 1905-1907 гг.

Как отмечает военный министр, весьма тяжелая служба, связанная с подавлением беспорядков, приводила к дроблению воинских частей, усталости солдат, приводившая в итоге к тому, что нижние чины сами «поддавались» агитации [1, т.1, с. 476].

Большинство военнослужащих, хотя и исполняли несвойственные им функции, видели все же свою главную задачу в защите Родины от внешнего врага. Юридически оформленный механизм вызова войск позволял местным гражданским властям часто обращаться за помощью к армии, но на этой почве было множество злоупотреблений. Войска вызывались по малозначительным причинам и не только для прекращения возникших беспорядков, но и для их предотвращения, а чины полиции пытались командовать солдатами.

Как разъяснял Главный штаб командующему МBO в 1906 г.: «по политическим соображениям» прекратить это не представлялось возможным, но меры все же предпринимались - военный министр часто обращается в МВД, с просьбой «о создании особой стражи» и усилении личного состава полиции.

Пока же воинские части должны сами лишь «одергивать» губернаторов и местные полицейские власти, которые, часто смотрели на воинские части, расположенные в пределах данной губернии или уезда, как на переданные в их собственное распоряжение. Поэтому, они считали возможным ставить им задачи и указывать цели действий. Случалось, что даже становые приставы осмеливались отдавать распоряжения, связанные с перемещением рот и эскадронов [10, с. 78]. Предлагалось прекратить подобную практику и направлять войска не по первому же требованию губернаторов, а лишь в случае действительной необходимости.

Армия становилась заложником политической борьбы, это прекрасно понимал А.Ф. Редигер, сообщая, что вовсе не собирался превращать войска в палачей или в «экзекуционные команды». Ведь это не являлось основной функцией армии, а войска в подобном случае способны «разнуздаться», превратиться в «грабителей», которых возненавидит население и перестанет выделять средства на содержание армии $[1$, т.2, с. 6].
Опасения оказались не напрасными: наблюдались случаи нападения на солдат, отправлявшихся в увольнение, толпа забрасывала камнями часовых, а в газетных статьях к слову «офицер» добавлялся эпитет «палач». Подавление революции обернулось многочисленными жертвами среди мирного населения: войска применяли реальную практику боевых действий, потому что иных способов воздействия не знали. Так, применяли артиллерию в многолюдной Москве в декабре 1905 г., где, уставшим от постоянного ожидания пули из-за угла, солдатам любой прохожий казался боевым дружинником.

Но задача была выполнена, А.Ф. Редигер, наконец, смог отметить, к своему удивлению, что уже в конце 1905 - начале 1906 гг. стали приходить вполне утешительные сообщения о том, что новобранцы ведет себя вполне удовлетворительно, да и занимаются «усерднее, чем когда-либо». Причину этого военный министр в более качественной работе офицеров и высказывал надежду, что армия легко восстановит свои былые качества, как только ей дадут возможность заниматься «своим» делом $[1$, т.2, с. 11].

Военному министру А.Ф. Редигеру, занимавшему эту должность до марта 1909 г., предстояло руководить проведением военных реформ 1905-1912 гг.

В заключение следует отметить, что обращение к воспоминаниям военного министра позволяет сделать некоторые выводы относительно масштабов революционного брожение в среде солдатских масс в годы первой русской революции 1905-1907 гг.

Следует проводить различие между понятиями «революционное движение в вооруженных силах» и «волнения в армии под влиянием как русско-японской войны 1904-1905 гг., так революции 1905- 1907 гг.».

Первое подразумевает восстания на флоте и в отдельных воинских частях, направленные против существующего государственного строя, второе - волнения в армейских частях и случаи неповиновения командованию вызванные, как действиями призванных из запаса солдат, требовавших скорейшей демобилизации, так и недовольством нижних чинов бытовыми условиями службы. Смешение же этих двух понятий способно существенно исказить представление о ситуации в армии в 1905-1907 гг.

\section{ЛИТЕРАТУРА}

1. Редигер А.Ф., История моей жизни. Воспоминания военного министра. - Т. 1-2. - М. Кучково поле, -1999. - 574с.

2. Голуб П.А, Большевики и армия в трех революциях. - М. Политиздат, 1977.- 320с.

3. Военные организации российского пролетариата и опыт вооруженной борьбы 1905-1917 гг. - М. Наука, 1974. - 417 с. 
4. РГВИА. - Ф. 1606. - 0п. 3. - Д. 169. - Л. 61.

5. Деникин А.И., Путь русского офицера. - М. Современник, 1991. - 300с.

6. Петров В.А., Очерки по истории революционного движения в русской армии в 1905 г. - М.-Л. Наука, 1964. - 427с.

7. РГВИА. - Ф. 1606. - 0п. 3. - Д. 169. - Л. 59.

8. Шумяцкий Б., Красноярское восстание 1905 года. - М. Новая Москва, 1926. - 56с.

9. Приказы по войскам Московского военного округа за 1907 г. - М. -1909.

10. РГВИА. - Ф. 1601. - 0n. 1. - Д. 229. - Л. 78.

○ Куксин Алексей Игоревич (aik71@bk.ru), Барыбин Алексей Валентинович (barybinav60@gmail.com), Васильев Алексей Георгиевич (alex_vas@ro.ru).

Журнал «Современная наука: актуальные проблемы теории и практики»

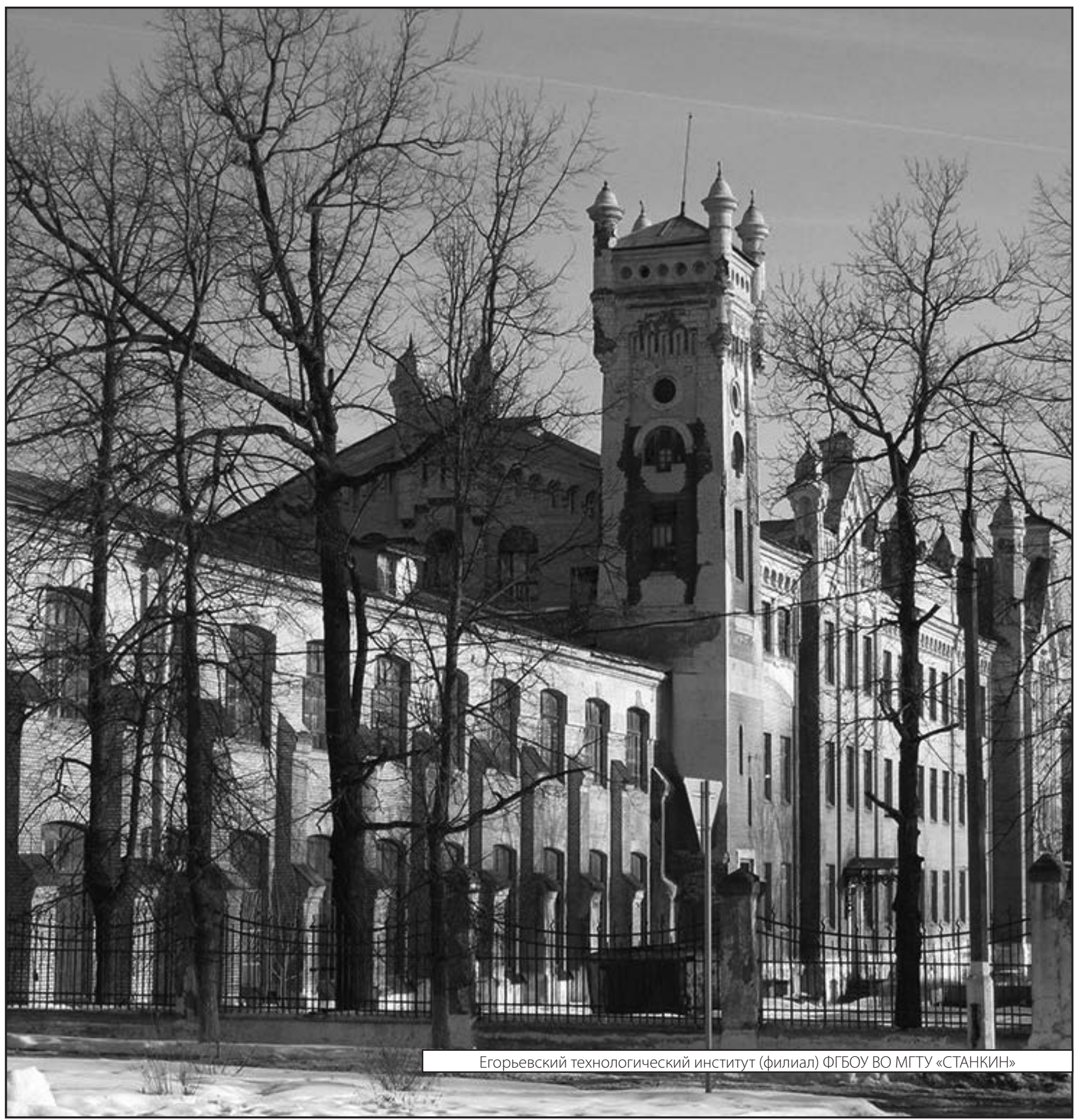

